\title{
CORRESPONDENCE
}

\section{Treatment of spontaneous pneumothorax - an ongoing debate}

\section{To the Editor:}

I read with great interest the Series paper on "Current aspects of spontaneous pneumothorax" by Schramel, Postmus and Vanderschueren, and would like to congratulate the authors for this well-documented review [1]. I disagree, however, with one of their conclusions, that "the choice of treatment should not depend on...the presentation with first time or recurrent spontaneous pneumothorax, but on the efficacy of treatment". I know that most Dutch colleagues react rather "interventionally" on the presence of air in the pleural space, and it may well be that immediate video-assisted thoracoscopic surgery (VATS) may have a superior cost-benefit ratio as compared to "conservative" therapy [2]. However, primary spontaneous pneumothorax is virtually always a very benign disorder: spontaneous real tension pneumothorax requiring immediate action is extremely rare and VATS every patient for the first episode furthermore means treating two thirds of patients for nothing (since they would never have recurrences anyway) [3]. So, even if it has a "superior cost-benefit ratio", I will not propose to my patients a first treatment which in fact is useful only in one third of cases! A simple small catheter manual aspiration, performed on an out-patient basis, is as useful in half of patients and bears absolutely no morbidity (or cost). If pneumothorax recurs, one can still present VATS to the patient: a randomized, prospective, multicentre study will be soon start- ing in Belgium to examine whether this approach is a valid one. Finally (but this is only an anecdotal remark), have the authors already treated colleagues - preferentially surgeons! - presenting with spontaneous pneumothorax? I would then strongly advise them to ask the "patients" preference on small catheter manual aspiration versus a $32 \mathrm{Ch}$ chest drain or VATS after the respective procedures, even taken into account a different recurrence rate, superior cost-benefit ratio, etc. Now this is an illuminating experience!

\section{Noppen}

Respiratory Division, Academic Hospital AZ-VUB, 101 Laarbeeklaan, B 1090 Brussels, Belgium.

\section{References}

1. Schramel FMNH, Postmus PE, Vanderschueren RGJRA. Current aspects of spontaneous pneumothorax. Eur Respir J 1997; 10: 1372-1379.

2. Schramel FMNH, Sutedja TG, Broker JCE, van Mourik JC, Postmus PK. Cost-effectiveness of video-assisted thoracoscopic surgery $v s$ conservative treatment for first time or recurrent spontaneous pneumothorax. Eur Respir $J$ 1996; 9: 1821-1825.

3. Miller AC. Management of spontaneous pneumothorax: back to the future. Eur Respir J 1996, 9: 1773-1774.

\section{REPLY}

\section{From the authors}

We thank M. Noppen for his interest and comments on our review. He clearly disagrees with our opinion that the choice of treatment of spontaneous pneumothorax should not depend on the presentation with first time or recurrent spontaneous pneumothorax, but on the efficacy of the treatment [1]

We think that M. Noppen will agree that the main goals of treating patients with spontaneous pneumothorax are to evacuate air from the pleural space and to prevent future recurrences. Many procedures can be used to achieve these goals, ranging from conservative treatment such as pleural aspiration to surgical intervention such as bullectomy and pleurectomy.

Simple small catheter aspiration, which M. Noppen suggested using in patients with first time spontaneous pneumothorax, will result in a recurrence rate ranging 16$52 \%$. If an open connection exists between the alveolar and pleural space at presentation in patients with spontaneous pneumothorax, aspiration will be ineffective to evacuate air from the pleural space. The patient will have to undergo this treatment once or several times again!

We showed in our retrospective analysis that videoassisted thoracoscopic surgery (VATS) is more cost-effective than in conservative treatment [2]. Bullectomy and pleurodesis were performed during VATS, while conservative treatment consisted of rest or pleural drainage. However, one may question the need for bullectomy, because in most cases bullae are probably not the actual cause of the pneumothorax [1].

Several studies indicated that the use of staplers for bullectomy were responsible for the postoperative course and the occurrence of recurrent pneumothoraces $[3,4]$. Pleurectomy as the only treatment proved to be very effective resulting in a recurrence rate of $1 \%$ !

From these findings it can be concluded that pleurodesis is the most effective treatment. To achieve adequate pleurodesis it is not at all necessary to perform VATS. We analysed our data on cost effectiveness in patients treated during VATS because this patient group was treated in a prospective way according to a standard protocol including VATS under general anaesthesia. From this standard protocol treatment and several other results, we have concluded that bullous degeneration is probably a symptom of the same abnormality in the lung, tissue, as the occurrence of a spontaneous pneumothorax [2-4]. This makes the almost universally accepted indication for bullectomy really 
questionable and it seems to be much more logical to ascribe the success rate of bullectomy to the way pleurodesis was achieved. A simple method to achieve pleurodesis is by talc poudrage [5]. Instead of introducing a small pleural catheter, one can easily introduce a $7 \mathrm{~mm}$ trocar through which talc poudrage can be performed. Epidural anaesthesia provides adequate analgesis during this procedure. If we had used this procedure this would have resulted in an additional $62 \%$ reduction of the costs in the previously mentioned study [2].

Treatment advice and decision should as much as possible be based on facts and figures, this is the only way in which every patient can be informed adequately, even if the patient is a surgical colleague!

F.M.N.H. Schramel

Dept of Pulmonary Diseases, St Antonius Ziekenhuis, Koekoekslaan I, 3435 CM Nieuwegein, The Netherlands.

\section{References}

1. Schramel FMNH, Postmus PE, Vanderschueren RGJRA. Current aspects of spontaneous pneumothorax. Eur Respir J 1997; 10: 1372-1379.

2. Schramel FMNH, Sutedja TG, Braber JCE, van Mourik JC, Postmus PK. Cost-effectiveness of video-assisted thoracoscopic surgery versus conservative treatment for first time or recurrent spontaneous pneumothorax. Eur Respir $J$ 1996; 9: 1821-1825.

3. Lim HP, Lim PJ, Hsieh MJ, Cheng JP, Chang CH. Thoracoscopic surgery as a routine procedure for spontaneous pneumothorax; results from 82 patients. Chest 1995; 107: 559-562.

4. Schramel FMNH, Sutedja TG, Janssen JP, Cuesta MA, van Mounk JC, Postmus PK. Prognostic factors in patients with spontaneous pneumothorax treated with videoassisted thoracoscopy. Diag Ther Endosc 1995; 2: 1-5.

5. Boutin C, Astoul P, Rey F, Mathur PN. Thoracoscopy in the diagnosis and treatment of spontaneous pneumothorax. Clin Chest Med 1995; 16: 497-503. 